\title{
Raman spectroscopic characterization of selenite reduction by the bacterium Azospirillum thiophilum in the presence of an increased concentration of sulphate \\ Vladimirova A.A., Kamnev A.A., Tugarova A.V.
}

Institute of Biochemistry and Physiology of Plants and Microorganisms, Russian Academy of Sciences, Saratov, Russia E-mail: vladimirova-nastyusha@bk.ru

Key message. In the biomass of A. thiophilum $\mathrm{BV}-\mathrm{S}$ grown in the presence of $7 \mathrm{mM} \mathrm{Na}_{2} \mathrm{SO}_{4}$, Raman spectroscopy showed a peak at $348 \mathrm{~cm}^{-1}$ (Se-S bond) in addition to a peak at $250 \mathrm{~cm}^{-1}$ (amorphous modification of Se).

Keywords: selenium, nanoparticles, Azospirillum thiophilum, Raman spectroscopy

Many microorganisms, including Azospirillum [1, 2], can reduce toxic selenium oxyanions to non-toxic $\mathrm{Se}^{0}$. Investigation of this phenomenon may be of interest for bioremediation, bio- and nanotechnology, etc. A. thiophilum (isolated from a sulphurcontaining source) is one of the least studied Azospirillum species. The features of the sulfur metabolism in A. thiophilum are of interest for studying possible ways of $\mathrm{S}$ involvement in the transformation of selenite ions. Note that A. brasilense was shown to form nanoparticles (NPs) containing both $\mathrm{S}$ and $\mathrm{Se}$ [3]. The aim of this work was to study $\mathrm{SeO}_{3}{ }^{2-}$ reduction in the presence of an increased concentration of $\mathrm{Na}_{2} \mathrm{SO}_{4}$ by A. thiophilum BV-S. The investigation was carried out in two systems: aerobic bacterial growth $\left(7 \mathrm{mM} \mathrm{Na}_{2} \mathrm{SO}_{4}\right.$ and $1 \mathrm{mM} \mathrm{Na}_{2} \mathrm{SeO}_{3}, 7$ days, $\left.31^{\circ} \mathrm{C}\right)$ and incubation in sterilised physiological saline solution $\left(7 \mathrm{mM} \mathrm{Na}_{2} \mathrm{SO}_{4}\right.$ and $5 \mathrm{mM} \mathrm{Na}_{2} \mathrm{SeO}_{3}, 1$ day, $32^{\circ} \mathrm{C}$ ). Cell biomass and NPs were investigated using transmission electron microscopy (TEM) and Raman spectroscopy. To identify differences in sulphur metabolism, a comparative bioinformatics analysis of the A. thiophilum BV-S, A. brasilense Sp245 and Sp7 genomes was performed using the NCBI Genome web resource (http://www.ncbi.nlm.nih.gov). TEM of biomass showed the presence of both cells and fairly uniform spherical electron-dense NPs, mainly localized outside the cells. Raman spectra of the biomass showed the appearance of peaks at $250 \mathrm{~cm}^{-1}$, which corresponds to $\mathrm{Se}^{0}$ in its amorphous modification, and at $348 \mathrm{~cm}^{-1}$, which corresponds to the Se-S bond. On the Raman spectra of biomass (after incubation), as well as of isolated NPs (both after growth and after incubation), only one peak at $250 \mathrm{~cm}^{-1}$ was observed (showing the absence of $\mathrm{S}$ in Se NPs). Bioinformatics analysis showed that $A$. thiophilum BV-S has a number of sulphur metabolism genes that are absent in A. brasilense Sp245 and Sp7. The investigation on transformations of selenite ions may be of interest both for practical applications and for clarifying biogeochemical transformations of $\mathrm{S}$ and Se compounds.

\section{Характеристика восстановления селенит-ионов бактерией Azospirillum thiophilum в присутствии повышенной концентрации сульфата методом спектроскопии комбинационного рассеяния \\ Владимирова А.А., Камнев А.А., Тугарова А.В.}

Институт биохимии и физиологии растений и микроорганизмов Российской академии наук, Саратов, Россия

\begin{abstract}
Аннотация. В биомассе штамма A. thiophilum BV-S, выращенного в присутствии 7 мM $\mathrm{Na}_{2} \mathrm{SO}_{4}$, методом спектроскопии комбинационного рассеяния показано наличие пика при $348 \mathrm{~cm}^{-1}$ (связь Se-S) в дополнение к пику при $250 \mathrm{~cm}^{-1}$ (аморфная модификация Se).
\end{abstract}

Ключевье слова: селен, наночастицы, Azospirillum thiophilum, спектроскопия комбинационного рассеяния Многие бактерии, включая азоспириллы [1, 2], способны к трансформации токсичных оксоанионов селена до нетоксичного $\mathrm{Se}^{0}$. Изучение этого феномена актуально для биоремедиации, био- и нанотехнологии и т.д. A. thiophilum (выделенный из серосодержащего источника) является одним из наименее изученных видов азоспирилл. Особенности серного метаболизма A. thiophilum интересны с точки зрения изучения возможных путей включения $\mathrm{S}$ в процесс трансформации селенит-ионов. Так, у A. brasilense отмечено образование наночастиц (НЧ), содержащих $\mathrm{S}$ вместе с $\mathrm{Se}$ [3]. Целью работы было исследование восстановления $\mathrm{Na}_{2} \mathrm{SeO}_{3}$ в присутствии повышенной концентрации $\mathrm{Na}_{2} \mathrm{SO}_{4}$ штаммом A. thiophilum BV-S. Исследование проводили в двух системах: аэробное выращивание бактерий (7 мM Na $2 \mathrm{SO}_{4}$ и $1 \mathrm{мM} \mathrm{Na} 2 \mathrm{SeO}_{3}, 7$ сут, $\left.31^{\circ} \mathrm{C}\right)$ и инкубация в стерильном физиологическом растворе $\left(7 \mathrm{mM} \mathrm{Na}_{2} \mathrm{SO}_{4}\right.$ и $5 \mathrm{mM}^{\circ}$ $\mathrm{Na}_{2} \mathrm{SeO}_{3}, 1$ сут, $32^{\circ} \mathrm{C}$ ). Биомассу клеток и НЧ исследовали с помощью просвечивающей электронной микроскопии (ПЭМ) и спектроскопии комбинационного рассеяния (СКР). Для выявления отличий в серном метаболизме проводили сравнительный биоинформатический анализ геномов A. thiophilum BV-S, A. brasilense Sp245 и Sp7 с помощью web-pecypca NCBI Genome (http://www.ncbi.nlm.nih.gov). ПЭМ биомассы показала присутствие как клеток, так и сферических электроноплотных достаточно однородных по размеру НЧ, преимущественно локализованных вне клеток. С помощью СКР выявлено, что при выращивании на спектрах биомассы наблюдаются пики при 250 см ${ }^{-1}$, что соответствует $\mathrm{Se}^{0}$ в аморфной модификации [2], и при $348 \mathrm{~cm}^{-1}$, что соответствует связи Se-S [3]. На спектрах КР биомассы (после инкубации), а также выделенных НЧ (как после выращивания, так и после инкубации) наблюдается лишь один пик при $250 \mathrm{~cm}^{-1}$ (отсутствие S в HЧ Se). Биоинформатический анализ показал, что A. thiophilum BV-S имеет ряд генов серного метаболизма, отсутствующих у A. brasilense Sp245 и Sp7. Изучение трансформации селенитионов является актуальной задачей как для практического применения, так и в фундаментальном отношении - для выяснения биогеохимических превращений соединений S и $\mathrm{Se}$.

1. Tugarova A.V. et al. Microb. Ecol. 68 (2014) 495-503.

2. Tugarova A.V. et al. New Biotechnol. 58 (2020) 17-24.

3. Vogel M. et al. J. Hazard. Mater. 344 (2018) 749-757. 